British Journal of Economics, Management \& Trade
8(2): XX-XX, 2015, Article no.BJEMT.2015.105
ISSN: 2278-098X
SCIENCEDOMAIN international
WwW.Sciencedomain.org

\title{
The Development of Polish Life Insurance Market in the Context of Austrian School - Client's Approach
}

\author{
Andrzej Janowski ${ }^{1^{*}}$ \\ ${ }^{1}$ Department of Economy and Management, The Higher School of Personnel Management, \\ Zagorowska str. 3a, 62-500 Konin, Poland.
}

Author's contribution

The sole author designed, analyzed and interpreted and prepared the manuscript.

Article Information

DOI: 10.9734/BJEMT/2015/17828

Editor(s):

$(1)$
$(2)$

Reviewers:

(2)

Complete Peer review History:

Original Research Article

Received $27^{\text {th }}$ March 2015

Accepted $21^{\text {st }}$ April 2015

Published 27 ${ }^{\text {th }}$ May 2015

\section{ABSTRACT}

Aims: The aim of this paper is to show the empirical relation between the insurance agents' specified personal qualities and the efficiency of life insurance companies in thecontext of future development perspectives, based on meta - analysis and conducted inthree domestic scientific projects and one international.

Study Design: "Identification of talent management dissemination level in life insurance companies", "Identification of competency management dissemination level in life insurance companies", "Identification of efficiency ratios implementation level in life insurance companies".

Place and Duration of Study: The territory of Poland and Lithuania, years 2005-2012.

Methodology: The research was conducted on the territory of Poland and Lithuania in the years 2005-2007 and 2011-2012, during the scientific project at the Higher School of Personnel Management in Konin. The aim of the above research was to identify the most important factors determining purchasing decisions to buy life insurance policies (Delphi method, questionnaires, storytelling).

Results: The research sample consisted of 476 insurance agents, 232 life insurance sales managers, and 796 clients of four biggest (referring to market shares) Polish insurance companies. All the above participants were asked the same questions to increase research reliability. The main factors of life insurance sales efficiency were evaluated and ranked. 
Conclusions: It seems to be authorized to claim, that the situation in the Polish life insurance market is complex and experiences (including sales strategies) from mature foreign markets are not suitable in the Central Europe. Moreover, results from the territory of Lithuania confirm that compensation system becomes (sooner or later) the root of financial problems and law suits risk exposure for life insurance companies.

Keywords: Agents; effectiveness; insurance; management; personality; provision.

\section{INTRODUCTION}

\subsection{Development and Knowledge}

The increase in the activities aimed at improving the material status of populations and crystalizing the concept of development programs was a derivative of the success of socialist bloc economies, including in particular, high growth rates in the initial period, which radically reflected global socio-economic conditions. Also, excellent results were obtained in the ideological sphere, and, additionally, the competition with western capitalist economic model was declared. Those conditions provided an incentive for the countries - colonizers to change attitudes towards subordinate colonies and to engage more in the development of the latter [1].

The institutions like the International Bank for Reconstruction and Development (also called the World Bank) and the International Monetary Fund became, at least by definition, the organizations supporting development as they supplied financial resources originating from the agencies created for this purpose. The declaration of decade of development by the United Nations launched a period of world community's interest in the development of the poorest countries. The reconstruction of Europe and the increasing interest in the material status of the poorest countries drew attention of the economics of development in the western mainstream of economic thought. Similar trends were also observed in the eastern bloc.

These intentions and interest, especially on the part of Western countries, although innovative at that time, implied a number of questions, including:

- what factors generate underdevelopment or stagnation,

- how can the relationship of these factors with the lack of development be explained,

- what action should be taken to eliminate the constant underdevelopment and the promotion of balanced development in the studied areas.
The attempt to answer the above questions caused proliferation of the theory of development, especially in the second half of the twentieth century. The aim of these investigations was to create a map of a coherent international system of logical thinking, which would respond to the questions mentioned by providing the intellectual basis for the design of development policy. In this process, the proposed theories of advanced logical systems are complementary in some areas and competitive in other areas too. The policy of development and implementation of economic development used the theoretical constructs for over a decade, accompanied by high expectations and hopes, eventually lost in the years 1960-1970. Also, there was disappointment with inefficiency in the coupling of theory and practice. Furthermore, not only did the stagnation occur in the countries with low level of development in the best scenario, but also the size of the gap increased, as compared to rich countries. In addition, the attempts to speed up the development process generated significant problems in the area of social adaptation and management. It was also not established experimentally, which of the theories of economic development had produced better results in identifying the determinants of economic development or description of good practices. Some of the views even generated counterproductive results proving the significance of other factors than those generated theoretically. Consequently, the choice constituted immense difficulty for both academics and practitioners.

In order to solve the problems, various scientists began to identify shortcomings in the existing theories of development. Critical remarks came from empirical observations, and they constituted pure speculations on the structure of theoretical constructs. Although the usefulness of criticism was undeniable, it was even more difficult to decide which of the existing theoretical constructs should be supported. Those evaluations included a significant mental defect: they did not provide a formal process of efficient 
choice between the competing theories (e.g. fundamental postulate of ethics emphasizes that some of the theories sanction capitalist individualism as a prerequisite for development. Other opposing theories emphasize the importance of socialist collectivism). Decisionmakers are placed in a difficult situation, as they have to choose from extremely ethical postulates of individualism and collectivism to generate an efficient path for organizational development. These two stances have been currently extended by introducing additional factors - relative sizes of private and public sectors. Hence, it seems reasonable to say about the non-existence of the criterion defining the frameworks within which the theories of development should be considered, and then accepted or rejected. Therefore, the selection of the criteria on the basis of which the model will be built is essential. The evaluation of strengths and weaknesses, as well as correctness of the theories (at the same time, the method of definition of these terms is irrelevant), requires considerable mental efforts, clarity of understanding, and their methodological and epistemological basis, in the context of the philosophical search for truth (adequatio intellectus et rei):

- clear specification of the content and object of research in the development economics,

- direct identification of methods and analysis of theoretical constructs suitable for the examined area,

- specification of the process of verification of scientific truth contained in the theory of development.

On the basis of the cognitive activities mentioned, it is possible to determine the applicability of the evaluation criterion of the scientific theory of development economics. However, it is not an easy process because no consensus has been found by academics because, so far, the mentioned criterion has been attempted to be established through postulates and criticisms of the existing theoretical structures [2]. However, the lack of agreement has not prevented the acquisition of the criterion from the available research papers on various theories of development.

Alternatively, on the basis of the discussion in the field of methodological and epistemological problems of traditional economic theory, the appropriate evaluation tool can be obtained for developing economies. In this case, the difficulty is posed by the general lack of well-developed intellectual relationship between philosophy and methodology of economics [3].

The debate mentioned in the methodology and epistemology of economics resembles philosophical positivism and instrumentalism restrictions. The participants of the mainstream, e.g. [4], [5], [6], [7] and [8], focused only on the assumptions of neoclassical economics. However, a deeper analysis indicates the existence of a general hypothesis referring to the above assumptions (Positivism and instrumentalism) that the capitalistic system represents the ultimate economic model. This idea, belonging to the realm of allegations, has led in discussions, to discover the historical and social importance of theorizing about economic phenomena. However, a historical context of this discourse does not totally contribute to the growth of understanding of the nature of the transformation process in relation to the feudal and industrial societies and certain stages of economic development. As such, it has not left too much research space for the assessment of the methodology of economics development. However, these debates, although they have many shortcomings, can inspire to ask questions about the scientific status of many theories of economic phenomena. These doubts in the field of methodological problems of economic knowledge are particularly important in the theories of economic development. They prove that the structural transformation of societies affects all aspects of human life and that the change from one developmental stage to another affects the material and psychological well-being of all the members of the society. On the basis of current scientific achievements of the author, it seems to be reasonable to emphasize the primacy of the Austrian school in the relevant area, which was confirmed by the results of empirical studies.

\subsection{Austrian School - The Birth of Praxiology}

The beginning of Austrian School of economics is associated with the publication of C. Menger's book entitled "Grundsätze der Volkswirtschaftslehre" (Principles of economics) in 1871. In this book, the author proves the error in the perception of the economy as a static, perfect being, remaining in a balanced state and possible to be described in the form of mathematical equations. In return, he proposes that the economy should be based on realistic 
subjectivity, never reaching the state of equilibrium. However, it constantly aims at reaching that state. Instead of typical homo economicus theoretical primacy of that period, the author promotes an individual as an entrepreneur making mistakes and undertaking risks while pursuing objectives. The mentioned work presented the result of observations of changes in prices on the Vienna stock exchange and own research in the field of political economy. The actual situation, emerging from research proposals, was far from a theoretical framework outlined by A. Smith or D. Ricardo. The approach proposed by C. Menger is based on the assumption that any actions are taken by individuals, pursuing their own activities marked by subjectivity in the area of economic activity. The author challenges the appropriateness of adoption of a homogeneous pattern of imaginary beings (also, social classes). He further argues that economic decisions concern the precise amount of specific objects rather than homogeneous goods of the producers or other aggregates, based, under certain conditions, on the subjective knowledge of the person making a decision, accompanied by uncertainties and limitations of knowledge. As a result, making simplifications (also, creation of models) aimed at universalization distorts the picture of reality, because every situation involving the expenditure of human energy is unique [9]. Therefore, it seems to be reasonable to say that the subjectivist perspective should be adopted during the formulation of economic claims. The basic idea of that approach is to assume that an individual makes an effort to reach a subjectively defined target of particular significance to entrepreneurs. This weight is determined by feelings and the premises subjectively existing at the time of the decision-making process. Still, it is dynamic and may be subject to change depending on the change in circumstances (as it is not possible to implement all the objectives at the same time, people make their subjective prioritization in compliance with the value assigned to them, as a result, the decisions can be made in the context of legitimacy and sequence of individual actions taken). Then, the means are arranged (referred to as necessary to achieve the pre-set goals). They are perceived as useful in the efficient management process, which are considered, depending on the subjective judgment, to be usable in the area of pursued goals. Therefore, the value of the aim is determined by the usability of a mean (however, it very rarely happens that just one operation needs to be performed to achieve an objective.
Therefore, people create a multi-step plan of action and are ready to take directly proportional effort to evaluate the objective pursued. The value to be ultimately assigned to the goals determines the subjective value of individual stages of action leading to it).

This relationship led $\mathrm{C}$. Menger to construct the concept of economic goods at a different level. The first level goods are consumer goods (ultimate purpose of action), as they directly meet the people's needs. However, not too many resources are suitable for immediate consumption. Most of them must first be transformed by human action, passing many intermediate stages, and the production process is not of a zero-one and immediate character, where produced goods are immediately converted into consumptive goods (according to the assumptions of typical school of economics). It is a multi-step process, whose duration is determined by the degree of complexity and multiplicity of steps. As the entrepreneur assesses measures in the context of their usefulness in achieving objectives, the mentioned evaluation is determined by boundary conditions. Thus, depending on available resources, the valuation of a given measure will be implemented on condition of usefulness of another measure. The author further claimed that, in the evolutionary process, involving innumerable people (each is characterized by subjective knowledge, experience and competencies) in the course of history, some emerging patterns of behavior facilitate effective functioning in a given society. They appear on the basis of replication of best patterns-i.e. those, which, in a given society, allow for the most efficient achievement of certain objectives (behaviors demonstrated by the most creative individuals in a given time). These patterns are shaped in a long-term, spontaneous and nonconscious process of verification of competitive behavior by trial and error. Owing to this process, the patterns that are gradually captured and disseminate dare those which coordinate mismatches in the society to the highest extent.

Also, L. Von Mises believed that no one can make more effective decisions than the people influenced by them. Moreover, the people who are most interested in taking decisions are always those who will feel the direct effects of it (for the supporters of objective classical school, the case, however, was not so obvious. As $L$. Von Mises wrote: "The illusion that rational organization of economic management is 
possible in the social system based on public ownership of the means of production has its roots in the theory of the values of classical economists. Persistence of this illusion stems from the fact that many modern economists could not consistently rethink the fundamental theory of subjectivist theory and draw definitive conclusions from it. (...) In fact, it is these errors that led socialist ideas to flourish" [10]. Therefore, every human need, any evaluative judgments and all the knowledge accumulated by an individual have their source in the creative abilities of humans (It constantly motivates them to act to improve their fate). When the sphere of human action is under threat of violence (the foundation of the main activities of state governments is based on it), the ability of individuals to generate information, owing to which they operate and the mismatches in the society are eliminated, is prevented. Consequently, the entrepreneurs lack incentives. They cease to strive for finding mismatches in the economy, thus lacking the force that would pull it towards the state of balance. In his views on entrepreneurial activities, L. von Mises defined a new field of knowledge: praxeology, detailed in his opus magnum "Human Action: A Treatise on Economics", published in 1949, where he emphasizes that humans differ from animals in that they have reason and free will. This means that, while the animals, through their behavior cannot make a choice (is determined by instinct, though it is often very complex and difficult to understand by the observer), humans, through their actions, always take sovereign decisions-as at any moment they can oppose their nature, which leads them to pursue different objectives. The basis of all human actions is people's choice between different forms of activity or passivity-a human act. Therefore, the claim that, in each activity, the theme of entrepreneurship and speculation (when taking actions, individuals pursue certain objectives for certain purposes, consistent with their subjective scale of values. The attainment of these objectives is conditioned by the time required to implement the measures they deem appropriate) is included and that the decisions, burdened with risks and connected with the selection of aims and the most effective methods of their achievement (entrepreneurial element) in the uncertain future (element of speculation), are taken, seems to be legitimate. Therefore, in order to take the optimal decision in given circumstances, it is necessary to gather adequate knowledge. However, since the objective common knowledge exists only in false economic theories, every person must personally get their desired details. Some of them can be found in the information created by someone else (imitation), the other ones must be discovered personally (for example, mismatches on the market), on the basis of observations of the environment and appropriate actions taken, or found in an unconscious way (for example, such knowledge is used, e.g. in the situations when people take decisions impulsively and then, asked about the reasons, reply that they have no idea - they just knew what they should do so. Psychology explains such situations by assuming that humans accumulate a large amount of information throughout their life. However, they are able to consciously realize and then examine only a few of them. The rest of knowledge is processed in a subconscious mind, which works much better, suggesting the result of analysis to the conscious part of the mind). This knowledge enables individuals to create an opportunity to make a profit (subjectively perceived benefits) appearing in their environment (becoming aware that it exists, and then taking actions to take advantage of it, only a human mind, which controls the operation and production, has the ability to create) [11]. As a consequence of this reasoning, the common point of view is criticized in that, the profit is formed by taking rewarded risks. They constitute only an additional cost of the actions of entrepreneurs. They do not affect the amount of generated profit (profit is not also made by taking maximizing decisions on buying and sellingentrepreneurship does not consist in a simple management of factors of production: "You do not need a diploma of completion of higher school of management to succeed in business. These schools prepare graduates to occupy subordinate positions, which require routine skills. Certainly, they do not educate entrepreneurs. Nobody can be trained to be the entrepreneur. People become entrepreneurs when they catch opportunity and fill a noticed gap. There is a general theoretical knowledge that can be learned through studies and practical knowledge of entrepreneurship, which is shaped by experience. One can be a great economic theorist, and, at the same time, bad entrepreneur. Gaining general knowledge gives no practical knowledge. These are two disjoint fields of knowledge acquired through different methods") in any way. Therefore, entrepreneurship allows people to constantly discover new information about potential targets and measures, and owing to their use in a creative activity, it provides a self-contained and 
independent of anyone's will the company's objective to reach balance. As a result, human activity is dependent on the selection (through trials and errors) of the most effective means to be achieved (these people make choices according to their personal scale of values. As a result, the action is taken to transform the state, which people perceive as less satisfactory to the one that may bring them the expected higher level of satisfaction). The above measures are, by definition, rare (otherwise, they would not constitute the subject of planning). Therefore, the decision-makers will carry out the most important objectives in the first place, and only later those that occupy next positions on their scale of preferences (according to the law of diminishing marginal utility). This activity is located in time, and also constitutes a rare good. Consequently, if people have an option to choose the same (in terms of the analyzed features) good now or in the future, they will always choose a present good (time preference law. According to W.S. Jevons and C. Menger, people usually prefer present to future goods. This is caused by the principle of conservation of energy - consuming is easier than saving. Therefore, the efforts connected with will and body, are always needed to postpone the use of funds already available today. People living in the present time and consuming their stocks, have a high time preference, and those saving or investing - low time preference) [12]. Moreover, a people plan their actions, taking into account their own predictions, which they create on the basis of theoretical knowledge. However, to use it, they have to refer their knowledge to specific present events, on the basis of previous experience, in which a given entity was involved. On this basis, the evaluation of possible scenarios of events takes place, so every a'priori human becomes an entrepreneur in a broad sense (operates under conditions of uncertainty while trying to assess the future course of events and to plan the activity most effectively. Relevant theoretical knowledge and experience determine specific actions and minimize uncertainty. Therefore, it seems to be reasonable to say about the absence of uniform predispositions in the decisions regarding own future actions). However, in contrast to economists, the entrepreneurs make efforts to construct their forecasts at the highest possible level of detail. The former ones have no basis for creating such predictions (as there are logical-deductive laws in economics, economists cannot make quantitative, geographical and time predictions only qualitative predictions can be made.
Expecting from economic theorists that they will make precise predictions about certain events results from the misunderstanding of economic reality and the nature of social sciences - when economists create such a forecast, they do not act as representatives of their area of expertise, but as entrepreneurs trying to guess the future course of events. Therefore, it is improper to claim that they are universal and logical implications of certain events, arising from the nature of human action in market conditions. The above mentioned conditions should rather be seen as value judgments regarding the strength of influence of various factors, issued on the basis of personal knowledge and experience).

\subsection{Phraseology and Efficiency in the Life Insurance Companies}

Insurance mediation means the mediator's paid services for the performance of actual or legal actions or implementation of insurance contracts. Insurance mediation can be conducted by agents exclusively, or insurance brokers. An insurance mediator realizes an action on behalf of the insurance company, named 'agency's actions (including: logging the clients, preparations for the conclusion of insurance contracts, as well as participation in the management and implementation of insurance contracts, also in the scope of damage, organization and supervision of agency actions), or a client oriented activity, called "broker's actions" (such as: taking actions to conclude insurance contracts, preparations for the conclusion of insurance contracts, as well as participation in the management and implementation of insurance contracts, also in the scope of damages). Thus, insurance companies must sell their products through the following channels of distribution: direct sales (provided by full-time workers), agency sales (by insurance agents) and brokerage (by insurance brokers). Although the direct sale conducted by the employees of insurance companies is characterized by a considerable quantitative volume, it does not reflect the efficiency of sales - the actions of mediation is also performed by (except the people working for insurance companies) bank employees, travel agents or even the postmen [Table 1].

In the context of the content of the above summary, it seems to be right to say that the activities of insurance agents are of particular importance to the performance of life insurance companies, because the quality of relationships 
with the clients of insurance agents has a major influence on purchase decisions. Also, R. Norman, when writing about the importance of service staff points to the fact that service activity is not marked by the extensive use of capital or intensive use of staff. Of crucial importance is the involvement of the employees providing services [14], which often have a purely emotional character. The authors emphasize that client orientation plays the most important role in insurance organizations, and the contact staff responsible for services is made up of a core group of employees in the organization. It is reflected in the claim [15], that the contact staff (along with resources and operating system) creates organizational top hierarchy owing to interactions with clients. It was the topic of research projects.

\section{MATERIALS AND METHODS}

\subsection{Research Methodology}

The research was conducted on the territory of Poland and Lithuania in the years 2005-2007 and 2011-2012, during the scientific project at the Higher School of Management in Konin. The research sample consisted of 476 insurance agents, 232 life insurance sales managers, and 796 clients of four biggest (referring to market shares) Polish insurance companies. The aim of the above research was to identify the most important factors determining purchasing decisions to buy life insurance policies (delphi method, questionnaires). All the above participants were asked the same questions to increase research reliability. The main factors of life insurance sales efficiency were evaluated and ranked. In this way, it was possible to get reliable answers to the same questions.

\subsection{Research Results}

\subsubsection{The factors determining the purchase of life insurance combined with fund - from the client's perspective}

The factors influencing the purchase of life insurance combined with fund were discussed by agents, managers and clients of insurance companies. Eleven basic factors were distinguished:

1. The amount of insurance premium,

2. Other insurance companies' offer,

3. Brand of insurance institution,

4. Participation in the market,
5. The number of additional options in the product,

6. The existence of a branch of an insurance institution in the client's place of residence,

7. Persuasive skill,

8. Multimedia presentation for the client,

9. Simulations of the increase in the value of the policy,

10. Agent's personal qualities,

11. Agent's general knowledge.

The respondents gave their answers by assigning the numbers from 1 to 5 to a given factor, where 1 was an invalid factor, and 5 was a very important factor. In this study, the points 7 , 10 and 11 were specified as characteristic determinants of L. Von Mises's theory for the purpose of the analysis, and they were correlated with the answers of the clients of life insurance companies.

\subsubsection{Ad. 7. Persuasive skill}

Statistical tests indicate that there is a significant dependency between the assessment of a persuasive skill, acting as a determinant factor in the purchase of life insurance combined with fund in the clients' opinion, and the insurance company, because persuasive skill is indicated as a very important determinant in purchasing life insurance by half of AVIVA, Amplico and ING clients, who evaluated this skill with 5.Among the PZU clients, this assessment is also dominant. However, less than $50 \%$ of the respondents evaluated it with 5 , and, if compared to other companies, it was often evaluated with 3 . [Tables 2, 2a].

The average values of ratings assigned to persuasion, acting as a decisive factor in purchasing life insurance, vary significantly in the opinion of customers.

The highest average score was attributed to this factor by ING clients - 4.54, not significantly lower by Amplico clients - and by AVIVA clients 4.52 - 4.50, and significantly lower by PZU clients - 4.12 [Tables 2b, 2c].

The situation described above is reflected in the research results of the next element determining the effectiveness of sales of insurance agents.

\subsubsection{AD. 10. Agent's personal qualities}

Similarly, as in the case of persuasion skill, statistical tests indicate that there is a significant 
dependency between the assessment of the agent's personal qualities, acting as a decisive factor in purchasing a life insurance combined with fund in the opinion of our clients, and insurance company [Tables $3,3 a]$.

The average values of ratings assigned to the agent's personal qualities, acting as a factor determining the purchase of life insurance, differ significantly in statistical terms in the clients' opinion. The highest average score was given by Amplico clients - 4.61, significantly higher than in the case of evaluation conducted by ING clients 4.42 , also statistically higher than in the case of AVIVA - and PZU clients 4.32 - 4.16 [Tables 3b, 3c].

Table 1. The service distribution channels of insurance companies in 2007-2014 [in\%]

\begin{tabular}{llllllll}
\hline Specification & $\mathbf{2 0 0 7}$ & $\mathbf{2 0 0 8}$ & $\mathbf{2 0 0 9}$ & $\mathbf{2 0 1 0}$ & $\mathbf{2 0 1 1}$ & $\mathbf{2 0 1 2}$ & $\mathbf{2 0 1 3}$ \\
\hline Direct sale & 27.3 & 22.9 & 32.4 & 36.8 & 34.6 & 28.8 & 40.2 \\
Agent sale & 66.3 & 72.5 & 62.5 & 52.6 & 55.9 & 63.0 & 56.8 \\
Brokers sale & 2.4 & 1.6 & 1.8 & 1.7 & 1.9 & 1.6 & 1.8 \\
Other & 3.9 & 3.0 & 3.3 & 8.9 & 7.7 & 6.6 & 1.1 \\
\hline \multicolumn{7}{c}{ Source: $[13]$} &
\end{tabular}

Table 2. Persuasive skill-investigation of the relationship (client rating)

\begin{tabular}{|c|c|c|c|c|c|c|}
\hline \multirow[t]{2}{*}{ Insurance company } & \multicolumn{5}{|c|}{ The client "buys" the agent who has convinced him/her } & \multirow[t]{2}{*}{ Amount } \\
\hline & 1 & 2 & 3 & 4 & 5 & \\
\hline \multirow[t]{2}{*}{ AVIVA } & 0 & 0 & 28 & 100 & 183 & 311 \\
\hline & $0.00 \%$ & $0.00 \%$ & $9.00 \%$ & $32.15 \%$ & $58.84 \%$ & $100 \%$ \\
\hline \multirow[t]{2}{*}{ Amplico } & 0 & 0 & 6 & 18 & 38 & 62 \\
\hline & $0.00 \%$ & $0.00 \%$ & $9.68 \%$ & $29.03 \%$ & $61.29 \%$ & $100 \%$ \\
\hline \multirow[t]{2}{*}{ ING } & 0 & 0 & 3 & 60 & 81 & 144 \\
\hline & $0.00 \%$ & $0.00 \%$ & $2.08 \%$ & $41.67 \%$ & $56.25 \%$ & $100 \%$ \\
\hline \multirow[t]{2}{*}{ PZU } & 4 & 6 & 69 & 74 & 126 & 279 \\
\hline & $1.43 \%$ & $2.15 \%$ & $24.73 \%$ & $26.52 \%$ & $45.16 \%$ & $100 \%$ \\
\hline \multirow[t]{2}{*}{ Amount } & 4 & 6 & 69 & 74 & 126 & 279 \\
\hline & $1.43 \%$ & $2.15 \%$ & $24.73 \%$ & $26.52 \%$ & $45.16 \%$ & $100 \%$ \\
\hline
\end{tabular}

Table 2a. Statistics for the data in Table 2

\begin{tabular}{lll}
\hline & $\chi^{2}$ & level $\mathbf{p}$ \\
\hline$\chi^{2}$ Pearson & 77.6253 & 0.0000 \\
$\chi^{2}$ NW & 82.5785 & 0.0000 \\
Contingency ratio & 0.2981 & \\
\hline
\end{tabular}

Source: own research

Table 2b. Persuasive skill - analysis of variance (client rating)

\begin{tabular}{lllllll}
\hline Insurance company & \multicolumn{6}{c}{ The Client "buys" the agent who has convinced him/her } \\
\cline { 2 - 7 } & Average & From standard Q25 & Median & Q75 & N \\
\hline AVIVA & 4.50 & 0.66 & 4 & 5 & 5 & 311 \\
Amplico & 4.52 & 0.67 & 4 & 5 & 5 & 62 \\
ING & 4.54 & 0.54 & 4 & 5 & 5 & 144 \\
PZU & 4.12 & 0.95 & 3 & 4 & 5 & 279 \\
Amount & 4.37 & 0.78 & 4 & 5 & 5 & 796 \\
Levene test & 0.0000 & & & & & \\
Variance analysis & 0.0000 & & & & & \\
\hline
\end{tabular}


Table 2c. Persuasive skill - NIR test (client rating)

\begin{tabular}{|c|c|c|c|c|c|}
\hline Agent & & AVIVA & AIG & ING & PZU \\
\hline NIR test & & 4.50 & 4.52 & 4.54 & 4.12 \\
\hline AVIVA & 4.50 & & 0.87 & 0.57 & 0.00 \\
\hline Amplico & 4.52 & 0.87 & & 0.82 & 0.00 \\
\hline ING & 4.54 & 0.57 & 0.82 & & 0.00 \\
\hline PZU & 4.12 & 0.00 & 0.00 & 0.00 & \\
\hline
\end{tabular}

Table 3. Agent's personal qualities - investigation of dependency (client rating)

\begin{tabular}{|c|c|c|c|c|c|c|}
\hline \multirow[t]{2}{*}{ Insurance company } & \multicolumn{5}{|c|}{ Agent's personal qualities } & \multirow[t]{2}{*}{ Amount } \\
\hline & 1 & 2 & 3 & 4 & 5 & \\
\hline AVIVA & 0 & 12 & 32 & 111 & 156 & 311 \\
\hline & $0.00 \%$ & $3.86 \%$ & $10.29 \%$ & $35.69 \%$ & $50.16 \%$ & $100 \%$ \\
\hline Amplico & 0 & 0 & 2 & & 40 & \\
\hline & $0.00 \%$ & $0.00 \%$ & $3.23 \%$ & $32.26 \%$ & $64.52 \%$ & $100 \%$ \\
\hline ING & $\begin{array}{l}0 \\
0.00 \%\end{array}$ & $\begin{array}{l}0 \\
0.00 \%\end{array}$ & $\begin{array}{l}6 \\
4.17 \%\end{array}$ & $\begin{array}{l}72 \\
50.00 \%\end{array}$ & $\begin{array}{l}66 \\
45.83 \%\end{array}$ & $\begin{array}{l}144 \\
100 \%\end{array}$ \\
\hline PZU & $\begin{array}{l}0 \\
0.00 \%\end{array}$ & $\begin{array}{l}10 \\
3.58 \%\end{array}$ & $\begin{array}{l}41 \\
14.70 \%\end{array}$ & $\begin{array}{l}122 \\
43.73 \%\end{array}$ & $\begin{array}{l}106 \\
37.99 \%\end{array}$ & $\begin{array}{l}279 \\
100 \%\end{array}$ \\
\hline Amount & $\begin{array}{l}0 \\
0.00 \%\end{array}$ & $\begin{array}{l}22 \\
2.76 \%\end{array}$ & $\begin{array}{l}81 \\
10.18 \%\end{array}$ & $\begin{array}{l}325 \\
40.83 \%\end{array}$ & $\begin{array}{l}368 \\
46.23 \%\end{array}$ & $\begin{array}{l}796 \\
100 \%\end{array}$ \\
\hline
\end{tabular}

Table 3a. Statistics for the data from Table 3

\begin{tabular}{lll}
\hline & $\chi^{2}$ & level $\mathbf{p}$ \\
\hline$\chi^{2}$ Pearson & 37.6687 & 0.0000 \\
$\chi^{2} \mathbf{N W}$ & 44.7398 & 0.0000 \\
Contingency ratio & 0.2126 & \\
\hline
\end{tabular}

Source: own research

Table 3b. Agent's personal qualities - variance analysis (client rating)

\begin{tabular}{lllllll}
\hline Insurance company & \multicolumn{5}{c}{ Agent's personal qualities } \\
\cline { 2 - 7 } & Average & From standard Q25 & Median & Q75 & N \\
\hline AVIVA & 4.32 & 0.81 & 4 & 5 & 5 & 311 \\
Amplico & 4.61 & 0.55 & 4 & 5 & 5 & 62 \\
ING & 4.42 & 0.57 & 4 & 4 & 5 & 144 \\
PZU & 4.16 & 0.80 & 4 & 4 & 5 & 279 \\
Amount & 4.31 & 0.76 & 4 & 4 & 5 & 796 \\
Levene test & 0.0004 & & & & & \\
Variance analysis & 0.0000 & Source: own research
\end{tabular}

Table 3c. Agent's personal qualities - NIR test (client rating)

\begin{tabular}{llllll}
\hline Agent's qualities & & AVIVA & Amplico & ING & PZU \\
\hline NIR test & & 4.32 & 4.61 & 4.42 & 4.16 \\
AVIVA & 4.32 & & 0.01 & 0.21 & 0.01 \\
Amplico & 4.61 & 0.01 & & 0.09 & 0.00 \\
ING & 4.42 & 0.21 & 0.09 & & 0.00 \\
PZU & 4.16 & 0.01 & 0.00 & 0.00 & \\
\hline
\end{tabular}


Also, in the area of general knowledge required of an insurance agent, the Clients emphasized the importance of knowledge in their decisionmaking process to purchase a life insurance combined with fund.

\subsubsection{AD. 11. Agent's general knowledge}

In this case, statistical tests indicate that there is a significant dependency between the assessment of the agent's general knowledge, acting as a determinant factor in the purchase of life insurance combined with fund in the clients' opinion, and the insurance company. The agent's general knowledge was most frequently rated at 4 by the insurance company's clients. However, Amplico and ING awarded this rating more often than PZU product buyers, who, in turn, more frequently than the clients of other companies, rated the knowledge below average [Tables 4, 4a].

The average values of ratings ofthe agent's general knowledge, acting as a factor determining the purchase of life insurance,vary significantly in statistical terms in the clients' opinion. The highest average rating was assigned to this factor by Amplico clients - 4.06, not significantly lower by AVIVAclients - 4.05 and ING clients - 4.02. These results are significantly and statistically higher than the average evaluation of PZU clients - 3.68 [Tables 4b, 4c].

In this research, agents as well as managers and clients, indicated persuasion skills as a basic determinant for purchasing life insurance combined with fund and the agent's personal qualities as a second determinant. Agent's general knowledge was considered to be less important (average ratings ranged from 3 to 4 ).

\subsection{Life Insurance Sector in Poland - Opportunities and Threats of Development in the Context of I. Von Mises Theory}

L. von Mises, in his work entitled 'Human Action', indicates that the most important performance factor in the organizations whose business is based on human activity is action. Furthermore, all his theoretical and epistemological assumptions are based on this key concept, which is defined by the author as a string of intentional actions - as characteristics based on the following assumptions [16]:

- objectives and measures are the two basic elements of the theory of action: a human acting consciously uses given measures to achieve a given goal,

- causality: category of means and ends presupposes the existence of the category of causality (hence the assumption that means are causes, and the goals are consequences),

- rationality: of course, the action may appear to be ineffective, may not lead to the attainment of a particular goal, due to the limited knowledge of the acting person. However, action is always rational (it is suited to its ultimate goal and knowledge possessed by the acting person), and choice, in turn, is based on evaluative judgment made subjectively by the acting person. Therefore, it cannot be considered as rational or irrational.

- ordinal scale of values: the final objectives pursued by the acting person may be material or spiritual, but (regardless of precise nature) their value and importance to the acting person are only subjective and assessed according to an ordinal scale. It is impossible to measure or calculate the value of subjective assessment.

assignment of values to measures: the measures of actions are relevant to the value and importance of the acting person, but as they are only tools used for achieving a particular purpose, their value is secondary (can be assigned only by taking into account the value of a goal),

- psychological gains or losses: considering the rarity of means and devoting them to the achievement of a given objective, the acting person must refrain from other goal, which is less valuable in his opinion. If the person's action is successful, it will bring him a subjective and mental profit, which constitutes a non-measurable and a positive difference between the value of the goal achieved and the value of a dedicated goal. If the operation is unsuccessful, the acting person will bear psychological losses,

- time: action always takes place in time, and its purpose is always embedded in the future since the present time cannot be changed,

- uncertainty: action also indicates the presence of change and uncertainty (if the future is certain, no action cannot change it, so there is no need for action). 
Table 4. Agent's general knowledge - dependency survey (client rating)

\begin{tabular}{|c|c|c|c|c|c|c|}
\hline \multirow[t]{2}{*}{ Insurance company } & \multicolumn{5}{|c|}{ Agent's general knowledge } & \multirow[t]{2}{*}{ Amount } \\
\hline & 1 & 2 & 3 & 4 & 5 & \\
\hline AVIVA & 4 & 12 & 50 & 145 & 100 & 311 \\
\hline & $1.29 \%$ & $3.86 \%$ & $16.08 \%$ & $46.62 \%$ & $32.15 \%$ & $100 \%$ \\
\hline Amplico & 0 & 4 & 6 & 34 & 18 & 62 \\
\hline & $0.00 \%$ & $6.45 \%$ & $9.68 \%$ & $54.84 \%$ & $29.03 \%$ & $100 \%$ \\
\hline ING & 3 & 3 & 30 & 60 & 48 & 144 \\
\hline & $2.08 \%$ & $2.08 \%$ & $20.83 \%$ & $41.67 \%$ & $33.33 \%$ & $100 \%$ \\
\hline PZU & 8 & 34 & 75 & 84 & 78 & 279 \\
\hline & $2.87 \%$ & $12.19 \%$ & $26.88 \%$ & $30.11 \%$ & $27.96 \%$ & $100 \%$ \\
\hline Amount & $\begin{array}{l}15 \\
1.88 \%\end{array}$ & $\begin{array}{l}53 \\
6.66 \%\end{array}$ & $\begin{array}{l}161 \\
20.23 \%\end{array}$ & $\begin{array}{l}323 \\
40.58 \%\end{array}$ & $\begin{array}{l}244 \\
30.65 \%\end{array}$ & $\begin{array}{l}796 \\
100 \%\end{array}$ \\
\hline
\end{tabular}

Table 4a. Statistics for the data from Table 4

\begin{tabular}{|c|c|c|}
\hline & $\chi^{2}$ & level $p$ \\
\hline$\chi^{2}$ Pearson & 51.1810 & 0.0000 \\
\hline$\chi^{2} \mathbf{N W}$ & 52.7745 & 0.0000 \\
\hline Contingency ratio & 0.2458 & \\
\hline
\end{tabular}

Table 4b. Agent's general knowledge - variance analysis (client rating)

\begin{tabular}{lllllll}
\hline Insurance company & \multicolumn{5}{c}{ Agent's general knowledge } \\
\cline { 2 - 6 } & Average & From standard Q25 & Median & Q75 & $\mathbf{n}$ \\
\hline AVIVA & 4.05 & 0.87 & 4 & 4 & 5 & 311 \\
Amplico & 4.06 & 0.81 & 4 & 4 & 5 & 62 \\
ING & 4.02 & 0.90 & 3.5 & 4 & 5 & 144 \\
PZU & 3.68 & 1.09 & 3 & 4 & 5 & 279 \\
Amount & 3.91 & 0.97 & 3 & 4 & 5 & 796 \\
Levene test & 0.0000 & & & & & \\
Variance analysis & 0.0000 & & & & & \\
\hline
\end{tabular}

Source: own research

Table 4c. Agent's general knowledge - NIR test (client rating)

\begin{tabular}{llllll}
\hline Agent's knowledge & & AVIVA & Amplico & ING & PZU \\
\hline NIR test & & 4.05 & 4.06 & 4.02 & 3.68 \\
AVIVA & 4.05 & & 0.88 & 0.80 & 0.00 \\
Amplico & 4.06 & 0.88 & & 0.76 & 0.00 \\
ING & 4.02 & 0.80 & 0.76 & & 0.00 \\
PZU & 3.68 & 0.00 & 0.00 & 0.00 & \\
\hline \multicolumn{2}{c}{ Source: Own research }
\end{tabular}

\section{CONCLUSIONS AND RECOMMENDA- TIONS}

In the context of referenced theoretical assumptions and the results of the conducted research, it seems to be legitimate to claim that the theory of L. Von Mises should be introduced to the management strategies of life insurance companies in the context of increase of the level of sales effectiveness. Insurance agents are entrepreneurs in accordance with legal requirements [17]. Therefore, the ultimate efficiency of the insurance company [18] depends on their activities, considered as a link of the largest distribution chain of life insurance combined with fund products. However, the risks associated with a strict commission system of remuneration of agents, which makes the mentioned way of selling relatively expensive and vulnerable to the risk of negative returns $[19]^{1}$, should be stressed.

\footnotetext{
${ }^{1}$ A. Janowski, B. Balewski, The effectiveness of insurance companies as a derivative of the existence of dysfunction in the commission based system of remuneration of agents, in: Organizacje w gospodarce innowacyjnej - aspekty społeczne, prawne, psychologiczne, wyd. AGH Kraków, 2008, pp. 31-42
} 
Moreover, it seems to be very important to mention that insurance agent, as an entrepreneur will mind his own business and profit. Therefore the most effective products for insurance company are not necessarily the financially attractive for intermediary. As a consequence clients follow the suggestions of insurance agents and buy the highest commission products. The veracity of mentioned sentence is widely observed in the large number of misselling law suits in Poland.

\section{ACKNOWLEDGEMENTS}

The author would like to thank Mr. Tomasz Jagodzinski - CEO AVIVA Lithuania for his support during conducting research as well as Blazej Balewski - The Dean of Economic and Management Faculty at WSKM Konin.

\section{COMPETING INTERESTS}

Author has declared that no competing interests exist.

\section{REFERENCES}

1. Janowski A. Ekonomiczne aspekty ubezpieczen. Bydgoszcz: UTP Publications; 2013.

2. Popper K. The Logic of scientific discovery. New York: Harper Torch Book; 1965.

3. Morgenstern O. Mathematical theory of expanding and contracting economics. Massatchusets: Lexington Books; 1976.

4. Hutchison T. Knowledge and ignorance in economics. Chicago: University of Chicago Press; 1979.

5. Machlup F. Methodology of economics and other social sciences. New York, Academic Press; 1978.
6. Friedmann M. Essays in positive economics. Chicago: University of Chicago Press; 1953.

7. Samuelson P. Operationalism in economic theory. Quarterly Journal of Economics. 1955;69:310-14

8. Blaug M. The methodology of economics. New York: Cambridge University Press; 1980.

9. Janowski A. The organizational effectiveness in the context of relationship marketing. Lvov: Wydawnictwo Politechniki Lwowskiej; 2012.

10. Von Mises L. Human action. A treatise on economics. Warsaw: Mises Institute; 2007.

11. Von Mises L. Planowany Chaos. Warszawa: Fijor Publishing; 2005.

12. Huerta de Soto J. Szkoła austriacka - ład rynkowy, wolna wymiana i przedsiębiorczość. Warszawa: Fijor publishing; 2010.

13. Committees of Financial Supervision. Available:www.knv.gov.pl

14. Norman R. Service management, strategy and leadership in service business: New York: John Wiley and Sons; 1984.

15. Rogoziński K. Nowy marketing usług. Poznan: Wyd. Akademii Ekonomicznej; 2000.

16. Von Mises L. Ludzkie działanie. Warszawa: Instytut Misesa; 2005.

17. Insurance Mediation Act [Journal of Laws No. 124, item. 1154].

18. Balewski B., Janowski A. The agent's personality versus effectiveness of life insurance companies. Economic Annals XXI. Lvov. 2013;84.

19. Janowski A, Balewski B. The effectiveness of insurance companies as a derivative of the existence of dysfunction in the commission based system of remuneration of agents. Krakow: Wyd. AGH Kraków. 2008;31-42.

(c) 2015 Janowski; This is an Open Access article distributed under the terms of the Creative Commons Attribution License (http://creativecommons.org/licenses/by/4.0), which permits unrestricted use, distribution, and reproduction in any medium, provided the original work is properly cited.

Peer-review history:

The peer review history for this paper can be accessed here: http://www. sciencedomain.org/review-history.php?iid=1062\&id=20\&aid=9453 